\title{
VIOLÊNCIA DO COTIDIANO E NO TRABALHO DE ENFERMAGEM: APREENSÕES E EXPECTATIVAS DE ALUNOS DE UM CURSO DE GRADUAÇÃO EM ENFERMAGEM DO RIO DE J ANEIRO
}

\author{
Violence of the everyday and in the nursing work: apprehensions and expectations \\ of the students from a course of graduation in nursing of Rio de J aneiro \\ Violencia del cotidiano y en el trabaj o de enfermería: aprehensiones y expectativas \\ de los estudiantes de un curso de pregrado en enfermería del Rio de J aneiro
}

\begin{abstract}
Resumo
Pesquisa de abordagem quantitativa, teve por objetivos: identificar as expectativas dos alunos de enfermagem sobre a violência do cotidiano; descrever as apreensões dos alunos de enfermagem sobre a violência no trabalho de enfermagem. A partir da aprovação pelo Comitê de Ética em Pesquisa da Escola de Enfermagem Anna Nery da Universidade Federal do Rio de Janeiro (EEAN/UFRJ), a pesquisa foi realizada com a participação de 52 alunos do 30 período letivo do Curso de Graduação em Enfermagem e Obstetrícia da EEAN/UFRJ. Para a coleta de dados utilizou-se um questionário com 14 perguntas abertas sobre as expectativas profissionais em relação ao significado da violência; à violência no cotidiano do aluno de enfermagem; e à violência no trabalho de enfermagem. Nos resultados, $62,9 \%$ dos alunos tinham como significação da violência, a agressão física; $57,7 \%$ afirmaram que a enfermagem é uma profissão de alto risco; e as cinco expressões escolhidas pelos alunos que melhor retratam a violência no trabalho da enfermeira foram: a falta de condições de trabalho, o cliente agressivo, trabalho em locais perigosos, baixos salários e abuso sexual.
\end{abstract}

Palavras-chave: Enfermagem. Violência. Ensino Superior.

\begin{abstract}
Quantitative research, that had as objectives: to identify the expectations of the students of nursing on the violence of the everyday; to describe the apprehensions of the students of nursing on the violence in the nursing work. From the approval of the Committee of Ethics in Research of the Anna Nery School of Nursing of the Federal University of Rio de Janeiro (EEAN/UFRJ), the research was carried through with the participation of 52 students from the $3 \mathrm{rd}$ period of the Graduation in Nursing and Obstetricses Course of the EEAN/ UFRJ. For the data collection a questionnaire was used with 14 opened questions about the professional expectations related to the meaning of the violence; to the violence in the everyday of the nursing student; and to the violence in the nursing work. In the results, $62.9 \%$ of the students had as meaning of the violence, the physical aggression; $57,7 \%$ had affirmed that the nursing is a profession of high risk; and the five expressions chosen for the students who better portray the violence in the work of the nurse had been: the lack of work conditions, the aggressive customer, work in dangerous places, low wages and sexual abuse.
\end{abstract}

\section{Keywords:}

Nursing. Violence. Education, higher.

\section{Resumen}

Inverstigación de enfoque cuantitativo, tuvo por objetivos: identificar las expectativas de los alumnos de enfermería sobre la violencia del cotidiano; y describir las aprehensiones de ellos acerca de la violencia en el trabajo de enfermería. A partir de la aprobación por el Comité de Ética en Pesquisa de la Escuela de Enfermería Anna Nery / HESFA / Universidad Federal de Rio de Janeiro (EEAN/UFRJ) - Brasil, la investigación fue realizada con 52 alumnos del 30 período lectiva del Curso de Pregado en Enfermería y Obstetricia de la EEAN/UFRJ. Para la recolección de datos, fué utilizado un cuestionario con 14 preguntas abiertas respecto a las expectativas profesionales en relación al significado de la violencia; a la violencia en el cotidiano del alumno de enfermería; y a la violencia en el trabajo de enfermería. En los resultados, $62,9 \%$ de los alumnos tenian, como significado de la violencia, la agresión física; 57,7\% afirmaron que la enfermería es una profesión de alto riesgo; y las cinco expresiones elegidas por los alumnos,que mejor describen la violencia en el trabajo de enfermería, fueron: carencia de condiciones de trabajo, cliente agresivo, actuación en locales peligrosos, bajos salarios y abuso sexual.

Palabras clave:

Enfermería. Violencia. Educación superior. 


\section{INTRODUÇÃO}

A presente pesquisa surgiu a partir da identificação do atual nível de violência a que estão submetidas às pessoas da cidade do Rio de Janeiro em geral e em particular no cotidiano de seu trabalho, e assim achamos por bem tratar da temática para saber como ela está se apresentando para os alunos de enfermagem. Sabe-se pela mídia e entre os próprios familiares nossos, que todos estão sendo expostos diariamente a alguma forma de violência e cada vez mais crescente.

A violência é um dos maiores legados do nosso passado, está presente em todos os segmentos da sociedade e evidencia-se nas suas várias manifestações, visíveis ou encobertas.

É um problema complexo que afeta a todos, sem distinção de estado ou de classe social, independente do sexo, idade, religião ou raça. Vem adquirindo grande significado social nos últimos tempos, não porque ocorra com mais freqüência e sim porque hoje é mais estudada, investigada e divulgada.

Os seus componentes perpassam a sociedade como um todo, independente de sua situação socioeconômica e cultural. Ela está associada a questões mais amplas, de natureza estrutural, revelando problemas institucionais, econômicos, sociais e políticos.

Há autores que vêm defendendo a tese de que 0 principal problema que enfrentará a humanidade, neste século XXI, será a violência, que vem se constituindo como uma das formas mais usuais de resolver os conflitos nas múltiplas redes (de relações familiares, interpessoais, de trabalho, de poder, ético-morais, organizativas, nacionais e internacionais).

Na busca dos significados da violência, alguns autores têm conceituações que delimitam o fenômeno à não realização de aspirações pessoais e/ ou coletivas assim entendidas:

A palavra violência vem do latim violare, significa infringir, quebrantar, abusar de outra pessoa por violação ou por astúcia. Se define também como uma força ou coação exercida sobre uma pessoa. (León ${ }^{1: 25}$ ).

Já para Corsi:2:28, a violência:

[...] é uma forma de exercício do poder mediante 0 emprego da força (seja ela física, psicológica, econômica, política...) e implica a existência de situações de superioridade ou de inferioridade reais ou simbólicas, que adotam habitualmente a forma de valores entre: pai-filho, homem-mulher, professoraluno, patrão-empregado, jovem-velho, etc, etc.
Podemos focalizar nas condutas violentas o emprego da força para resolver conflitos. É uma forma de exercício de poder para eliminar aqueles obstáculos que se interpõem nas nossas decisões, ações. Geralmente, a conduta violenta é possível dada a condição de desequilíbrio de poder. Este pode estar motivado culturalmente ou pelo contexto ou produzido por manobras nas relações interpessoais de controle na relação.

Esse desequilíbrio de poder dentro da relação poderá ser momentâneo ou permanente. Quando é permanente, as causas são, entre outras, de ordem econômica, cultural, institucional, e, quando momentâneo, se explica por si só, as contingências ocasionais (força física, coação, pressão: verbal, emocional, sexual).

Por essa razão, para que uma conduta seja considerada violenta tem que existir um certo desequilíbrio de poder, real ou simbólico, vinculado ao contexto, às relações interpessoais, familiares, no trabalho. Além do mais, as relações de poder não são estáticas; elas também estão relacionadas com as questões de gênero, etnias, nível socioeconômico, desde que uns tenham mais ou menos poder e possam em um determinado momento exercê-lo, daí existirem as violências visíveis e invisíveis. Neste sentido, assim comenta Dominguez et a| |32: $^{3}$ :

Se antes a violência direta (principalmente a guerra) aparecia (e ainda hoje aparece), como uma violência visível, outros tipos de violência, como a estrutural, permaneceram encobertos por muito tempo.

A Organização Mundial da Saúde 4 aponta que uma das razões pelas quais a violência tem sido considerada como uma questão de saúde pública é a falta de uma definição clara dessa problemática, pois, devido à ampla variedade de códigos morais existentes nos distintos países, essa temática é uma das questões mais difíceis de ser abordada nos fóruns mundiais. Para a referida Organização ${ }^{4: 3}$, a violência:

é o uso deliberado da força física ou do poder e que seja em grau de ameaça ou efetiva, contra si mesma, outra pessoa, grupo ou comunidade, que cause ou tenha muitas probabilidades de causar lesões, morte, danos psicológicos, transtornos do desenvolvimento ou privações.

A Organização Internacional do Trabalho 5:3 conceitua a violência no ambiente do trabalho como "toda ação incidente ou comportamento mediante 0 qual uma pessoa é agredida, ofendida, prejudicada ou humilhada por outra pessoa em seu trabalho ou como 
consequência do mesmo". Os estudos nesta área têm mostrado que a violência permeia o cotidiano dos trabalhadores em geral e o seu crescimento tem sido gradativo e por vezes silencioso na nossa sociedade causando repercussões no cotidiano do trabalho e na saúde dos trabalhadores.

\section{Objetivos}

1. Identificar as expectativas dos alunos de enfermagem sobre a violência do cotidiano

2. Descrever as apreensões dos alunos de enfermagem sobre a violência no trabalho de enfermagem.

\section{METODOLOGIA}

\section{Tipo de Estudo}

Estudo de natureza empírico-descritiva, com abordagem quantitativa, levando-se em consideração a codificação da "face mensurável da realidade social", em que para Andrade(6:14-15), "... os fatos são registrados, analisados, classificados e interpretados, sem que o pesquisador interfira sobre eles".

\section{Amostra}

Alunos do 30 período do Curso de Enfermagem e Obstetrícia da Escola de Enfermagem Anna Nery da Universidade Federal do Rio de Janeiro. De uma turma de 55 alunos, $52(94,5 \%)$, responderam ao questionário por estarem em sala de aula. Os 3 alunos $(5,5 \%)$ que não responderam ao questionário não estavam presentes no momento da distribuição do questionário. Os sujeitos pesquisados estavam naquela ocasião vivenciando situações de ensinoaprendizagem relacionadas com a saúde do trabalhador e responderam a um questionário composto de 14 perguntas abertas sobre as seguintes questões: As expectativas profissionais em relação ao trabalho de enfermagem; o significado da violência; a violência no cotidiano do aluno de enfermagem e a violência no trabalho de enfermagem.

Por ter sido uma opção trabalhar com os alunos do 30 período do Curso de Enfermagem, a presente pesquisa não comporta generalizações em termos do entendimento que os alunos de enfermagem têm acerca da violência, cabendo assim o prosseguimento de novas pesquisas envolvendo alunos dos demais períodos letivos.

\section{Cenário}

A sala de aula, localizada no Centro de Ciências da Saúde, da Universidade Federal do Rio de Janeiro, na Ilha do Fundão/Rj.

\section{Coleta de Dados}

0 questionário utilizado foi elaborado pelas pesquisadoras visando atender aos objetivos propostos. Os alunos receberam uma orientação sobre a pesquisa em sala de aula e orientados quanto a importância da temática, ou seja, em adquirir subsídios para alterarmos/incluirmos questões no currículo do curso de graduação tendo em vista as questões referentes a saúde do trabalhador. Apesar de terem uma professora como pesquisadora, aos alunos foi assegurada a garantia que não seriam punidos ou prejudicados em avaliação caso não quisessem participar. 0 questionário não precisou ser assinado e foi devolvido separado do Termo de Consentimento Livre e Esclarecido para não se identificar 0 aluno e suas respostas.

\section{Aspectos Éticos}

Procurou-se atender aos princípios da bioética, contidos na Resolução 196/96, do Conselho Nacional de Saúde/ Ministério da Saúde, a saber: autonomia, beneficência, não maleficência e justiça. A autonomia dos sujeitos está garantida pela apresentação do Termo de Consentimento Livre e Esclarecido. 0 grupo de alunos receberam o Termo em sala de aula. A professora, uma das autoras da pesquisa, esclareceu 0 objeto e os objetivos da pesquisa assim como todo 0 seu procedimento de coleta de dados e análise. Os benefícios foram esclarecidos ao grupo garantindo que ao participar da pesquisa não estariam correndo nenhum risco (beneficência e não maleficência). Foi importante esclarecer aos alunos que mesmo que não quisessem participar não estariam comprometidos, ou seriam perseguidos em termos de nota ou avaliação (justiça e equidade). A participação dos sujeitos do estudo foi voluntária e trouxe contribuições para a linha de pesquisa das autoras bem como contribuiu na produção de conhecimento que dará subsídio para uma melhor formação do aluno de enfermagem com relação ao trabalho desta categoria profissional. 0 comitê de Ética em Pesquisa da Escola Anna Nery/UFRJ aprovou o projeto em 26 de outubro de 2004.

\section{ANÁLISE E DISCUSSÃO DOS DADOS}

A avaliação dos dados baseou-se nas expectativas e apreensões da amostra estudada sobre a violência e o trabalho de enfermagem.

À exceção dos dados referentes ao sexo e à idade, os demais dados foram tabulados e organizados estatisticamente sob a forma de quadros tendo em 
vista que o questionário era composto de questões abertas. $\mathrm{Na}$ apresentação e análise dos dados, foram realçados os resultados que apareceram com as maiores freqüências.

Dos 52 participantes, $85,4 \%$ eram do sexo feminino e 14,6\% do sexo masculino; Destes, $40,4 \%$ estão situados na faixa entre 20 e 22 anos; $30,8 \%$ entre 17 e 19 anos; $11,5 \%$ entre 23 e 25 anos e $17,3 \%$ não responderam este quesito. Evidencia-se que a enfermagem continua sendo uma profissão em que a predominância é do sexo feminino.

\section{Expectativas profissionais em relação ao trabalho de enfermagem}

Sobre as expectativas profissionais em relação ao trabalho de enfermagem, $30,8 \%$, responderam que este deve direcionar-se a grupos populacionais, nos aspectos da promoção da saúde e da prevenção de seus agravos. Essa constatação demonstra que estes alunos já tem 0 entendimento de que no processo saúde-doença, são importantes os aspectos da promoção da saúde como enfoque mais amplo e abrangente, significando as intervenções sobre as populações, bem como os referentes às intervenções individuais e pontuais ${ }^{7}$, ou sejam, a prevenção de doenças.

Ainda neste quesito, $27 \%$ referiram-se às questões de compensações financeiras e com o mesmo percentual aparece a questão de ter um bom emprego. Esse fato reforça a preocupação desses futuros enfermeiros em relação ao mercado de trabalho, tendo em vista que nas sociedades capitalistas, como é o caso do Brasil, os problemas derivados da hegemonia do mercado neoliberal, a inclusão social está diretamente relacionada com o poder de compra, em que o cidadão só é tipificado como cliente, se tiver renda, se tiver poder aquisitivo.

Os resultados indicaram que $69,2 \%$ dos pesquisados têm como significação da violência a agressão física. Palácios et $\left.a\right|^{8}$. em pesquisa realizada a respeito da violência no trabalho no setor saúde evidenciaram que os auxiliares representam $12 \%$ dos profissionais agredidos fisicamente, seguido pelo grupo de enfermeiras, 9,9\% e pelos médicos com $5,7 \%$, respectivamente.

Quanto às questões referentes à violência no seu cotidiano, 63,3\% apontaram o medo/apreensão/receio; para $21,9 \%$, a insegurança enquanto que $14,0 \%$ indicaram indignação/raiva/ódio/revolta/aversão. Neto e cols..$^{9: 33}$ ao referirem-se à violência no Estado do Rio de Janeiro, são enfáticos ao declararem que: [...] percebe-se um número crescente de pessoas sobressaltadas e indignadas com 0 agravamento dos problemas sociais, expresso sobretudo nas diferentes formas de violência que permeiam o tecido social.

A OlT ${ }^{5: 57}$ faz a seguinte afirmativa:

Várias ocupações do setor saúde como, por exemplo, a do médico, enfermeira e trabalhador social encabeçam a lista das ocupações em que se registram elevados índices de estresse. 0 acesso das pessoas a uma atenção sanitária de qualidade pode sentir-se ameaçado quando os agentes de atenção sanitária trabalham sob tensão devido à escassez de pessoal, aos baixos salários, ao trabalho por turnos, trajetos perigosos até ao local de trabalho e outras circunstâncias particularmente vulneráveis à violência.

Os profissionais que lidam com situações de violência tendem a conviver com pensamentos, sentimentos e sensações que podem ser prejudiciais à saúde física e mental. Como professoras e aluna de enfermagem, preocupamo-nos com o aprendizado desse aluno permeado pelo medo, sobressaltado e sem tranqüilidade para aprender a apreender o conteúdo ensinado.

\section{Apreensões dos alunos sobre a violência no trabalho de Enfermagem}

Nesta questão, 28,8\% apontaram o abuso do poder; $26,9 \%$, a falta de respeito; $21,1 \%$, a agressão física; $17,3 \%$, situações de risco. É importante notar que, mesmo sendo alunos que estão no 30 período do curso, já conseguem identificar que 0 abuso do poder e a falta de respeito aqui entendidos como Assédio Moral, conceituado por Barreto 10:2 como: "um conjunto de sinais que visam cercar e dominar 0 outro e revelados por atos e comportamentos agressivos, realizados, freqüentemente, por um superior hierárquico, contra um ou mais pessoas", está presente no interior da organização do trabalho de Enfermagem.

Em relação às profissões que mais sofrem violência, $42,2 \%$ dos alunos informaram ser os policiais, seguidos de $26,6 \%$ de todas as profissões e $15,3 \%$, a enfermeira. Para a OIT 5:57:

[...] é provável que as enfermeiras experimentem em geral mais a violência que outras ocupações, pois como a grande maioria da força de trabalho ser integrada por mulheres, a dimensão do gênero que tem o problema, é evidente.

Dos respondentes, $57,7 \%$ afirmaram que a enfermagem é uma profissão de alto risco e os tipos de trabalho em que as enfermeiras sofrem mais violência são aqueles desenvolvidos nas emergências e nas favelas, evidenciados pelos percentuais de 25,0 $\%$ e $23,1 \%$ respectivamente. 
Uma das constatações encontradas por Deslandes ${ }^{11: 177}$ ao estudar a interferência cotidiana da violência na dinâmica organizacional do setor de emergência de dois hospitais públicos da cidade do Rio de Janeiro, é que se trata de:

um processo de trabalho que impõe doses consideráveis de sofrimento aos seus trabalhadores, seja pela própria natureza da atividade (lutar contra a morte e a incapacitação), seja pelas condições que thes são impostas em determinados processos de gestão.

Em relação às favelas e às periferias da cidade, têm sido locais de praxe de atuação das enfermeiras, que estão retomando o modelo assistencial utilizado no início da enfermagem no país, em que a visita domiciliar era uma das atividades mais importantes do desempenho das enfermeiras, principalmente de atendimento na área da Saúde Pública. Hoje aqueles locais são reconhecidos como áreas de grande violência devido ao tráfico de drogas, disputa de poder entre as facções criminosas e das ações de grupos de extermínio, conhecidos popularmente como justiceiros.

Equivocadamente alguns segmentos da sociedade unificam os habitantes da periferia, dos morros e das favelas nas categorias de vadios, criminosos e marginais. Todos os processos acontecidos e que continuam acontecendo se refletem na inclusão seletiva de poucos e não universalista de grupos populacionais alijados, em que este tecido social está imensamente fragmentado, gerando, assim, a organização social da violência.

Os alunos foram indagados se consideraram a violência no trabalho quando escolheram a Enfermagem, e $94,2 \%$ informaram que este fato não interferiu na escolha profissional, enquanto 3,8\% disseram que sim e 2,0\% não responderam esta questão. Estes dados se tornam relevantes no sentido de que a temática violência no setor saúde seja incluída nos currículos dos cursos de enfermagem, até porque, de acordo com Palácios ${ }^{9: 7}$, não foram encontrados estudos específicos sobre a violência como objeto privilegiado de análise entre o pessoal de enfermagem.

As cinco expressões escolhidas pelos alunos para melhor retratarem a violência no trabalho da enfermeira foram: falta de condições de trabalho (46,15\%); cliente agressivo (30,8\%); trabalho em locais perigosos $(30,8 \%)$ baixos salários $(30,8 \%)$ e abuso sexual $(28,8 \%)$.

A falta de condições de trabalho e os baixos salários referidos pelos alunos estão associados à ofensiva do mercado atual que trouxe conseqüências nefastas para todos: quebra de direitos sociais, reformas no contrato de trabalho, terceirizações, crescimento do setor informal, trabalho em casa e as cooperativas; baixos salários e sobrecarga de trabalho; recursos materiais insuficientes e/ou inexistentes; aumento do subemprego e precarização do emprego; flexibilização dos contratos de trabalho. Assim sendo, os trabalhadores estão sendo reduzidos, enfraquecidos e submetidos ao chamado processo de flexexploração, vivendo as incertezas e os múltiplos medos. ${ }^{12}$

Em relação à agressividade da clientela apontada pelos alunos, denota-se que este fato está relacionado com as histórias de vida de grande parte dessa clientela. Para Moura et al. ${ }^{13: 113}$ essa clientela:

Em geral, é persuadida de tal modo que suas realizações efetivas, somáticas e mentais estão geralmente estão situadas abaixo de suas aspirações pessoais, pois continua não tendo oportunidades de ser incluída socialmente, tornando-se órfã do Estado e por vezes, arregimentada para um universo brutal e impiedoso, onde 0 respeito e a hierarquia têm por base a violência.

Alguns locais utilizados como campo prático pelos alunos são reconhecidos na cidade como ambientes onde professores e alunos estão sujeitos a roubo, assaltos e ameaças, além das agressões advindas de parte da clientela sob seus cuidados. Em relação ao trabalho realizado pelas enfermeiras em locais perigosos, comenta a OIT ${ }^{5: 59}$ que:

Situações e Ocupações que apresentam um risco especial de violência estão os trabalhadores de assistência domiciliar e comunitária, os trabalhadores dos serviços noturnos, os trabalhadores dos serviços de atenção psiquiátrica, os trabalhadores das unidades de urgência.

Estes são alguns dos cenários em que as enfermeiras atuam e os alunos de enfermagem desenvolvem experiências de ensino/aprendizagem. Os alunos expressaram que o assédio sexual, como modalidade de violência no trabalho. No assédio sexual, as vítimas são majoritariamente as mulheres Este fato guarda relação com a enfermagem, profissão em que há a predominância do sexo feminino.

\section{CONSIDERAÇÕES FINAIS}

A violência nas sociedades de classes é sistêmica, ou seja, integra sua natureza e faz das relações praticadas dentro da produção e se transmite a todos 
os outros espaços sociais, como os serviços públicos, da rua e o doméstico, colonizados pelos valores simbólicos e materiais do trabalho, em que a violência pode estar presente.

A história dos direitos humanos assim como a história das regulamentações jurídicas das violências ainda não foram concretizadas. Torna-se necessário a articulação efetiva dos setores da sociedade de modo que haja maior potencial de impacto sobre as situações de risco permanente e na promoção da saúde física e mental dos trabalhadores de saúde (entre eles os alunos de enfermagem) em seus ambientes de trabalho e estudo As mudanças ocorridas nas formas de organizar 0 mundo do trabalho, produzir e acumular riquezas marcaram as últimas décadas do século passado.

Mesmo que se considere a banalização das diferentes formas de violência, as questões demandam reflexão e ação frente às suas diferentes necessidades, visto que a problemática aqui colocada repercute diretamente no cidadão, na família e na sociedade,

\section{Referências}

1. León IA. Violencia y sexualidad. La Habana: Instituto Cubano del Libro Editorial Científico-Técnica; 1998.

2. Corsi J. Violência familiar: uma mirada interdisciplinaria sobre um grave problema social. México(MX): Paidós; 1995.

3. Dominguez R, Sanseviero R, Vasquez. I. 0 estado da paz e a evolução da violência: a situação da América Latina/Centro Internacional de Investigação para a Paz das Nações Unidas. Tradução de Maria Dolores Prades. Campinas(SP): Ed UNICAMP; 2002.

4. Organización Mundial de la Salud /OMS. Informe mundial sobre la violencia y la salud. [on line]; 2003; [ citado 26 out 2003]. Disponivel em: http://www.who.int/entity/violence_injury-prevention/violence/ world-report/en/abstract\%.

5. Organización Internacional del Trabajo/OIT. Informe para discusión en la reunión de expertos encargada de elaborar un repertorio de recomendaciones prácticas sobre la violencia y el estrés en el sector de los ser viços: una amenaza para la productividad y el trabajo decente. [ on line] 2003 8-15 oct; [ citado 26 out 2003] : Disponível em: www.lo.org/ public/spanish/dialogue/setor/techmeet/mevsw03/index.htm

6. Andrade MM. Como preparar trabalhos para cursos de pósgraduação: noções práticas. São Paulo (SP): Atlas; 1995. p. 14-15.

7. Buss PM. Uma introdução ao conceito de promoção da saúde. In: Czerina D, Freitas CM, organizadores. Promoção da saúde: conceitos, reflexões, tendências. Rio de Janeiro (RJ): FIOCRUZ; 2003.

8. Palácios M. Violência no setor saúde: Rio de Janeiro-Brasil. Relatório preliminar de pesquisa. Rio de Janeiro (RJ):UFRJ; 2001/2002. Projeto realizado em cooperação com OIT, CIE, OMS, ISP.

9. Neto ON. Nem soldados nem inocentes: juventude e tráfico de drogas no Rio de Janeiro. Rio de Janeiro (RJ): FIOCRUZ; 2001. assim como na saúde dos profissionais de saúde, realçando-se as enfermeiras, uma vez que são grandes as fontes de pressão a que estão submetidas no exercício de suas funções, tornando-as vulneráveis aos riscos derivados do contexto social e institucional até porque, para Minayo $\&$ Souza ${ }^{14: 8}$ :

0 tema da violência não entrou no setor saúde de forma natural. Ele se impôs e assim o fez por muitos fatores. 0 setor saúde olhou para o fenômeno da violência, como um expectador, um contador de eventos, um reparador de estragos provocados pelos conflitos sociais.

$\mathrm{Na}$ área da enfermagem, essa constatação é um fato. Cabe prosseguir o estudo agora optando-se pelo tipo qualitativo para que se possa melhor identificar a subjetividade desses cidadãos, alunos de enfermagem, no enfrentamento de situações hostis que vivenciam ao longo do seu cotidiano.

10. Barreto M. Assédio moral: o risco invisível no mundo do trabalho. Jornal da Rede Feminista de Saúde.[ on line]; 2005; [citado 01 março 2005] . Disponivel em: http://www.redesaude.org.br/jr25/html/ body_jr25-margarida.html

11. Deslandes SF. Frágeis deuses: profissionais da emergência entre os danos da violência ea recriação da vida. Rio de Janeiro (RI): FIOCRUZ; 2002.

12. Bourdieu P. A essência do neoliberalismo. Margem 1998 dez; 8: 46-58

13. Moura FJMM, Lisboa ML. A violência e a sua origem nas interfaces com o mundo do trabalho da enfermeira de saúde pública. Esc Anna Nery Rev Enferm 2005 ago; 9(1): 108-15.

14. Minayo MC, Souza E.R. É possível prevenir a violência? Reflexões a partir do campo da saúde pública. Abrasco 1999; 4(1): 7- 23

\section{Sobre as Autoras}

\section{Marcia Tereza Luz Lisboa}

Professora Adjunto do Departamento Enfermagem Fundamental da EEAN I UFR]; Doutora em Enfermagem e membro da Diretoria do Núcleo de Pesquisa Enfermagem e a Saúde do Trabalhador do DESP / EEAN/UFRJ.

\section{Francimar de Jesus Moreira de Moura}

Doutoranda em Enfermagem (Núcleo de Pesquisa Enfermagem e a Saúde do Trabalhador), DESP/ EEAN/UFR]; Professora do Curso de Enfermagem da Universidade Gama Filho. Professora aposentada da EEAN/UFRJ.

\section{Lidiane Dias Reis}

Aluna do Curso de Graduação em Enfermagem e Obstetrícia da EEAN/UFR]. 